\title{
It's Possible to Predict a Decreased Bactericidal Effect of Biocides, through Antibiotic Resistance in ICU: Study Using a Large Sample of Bacteria and Multivariate Analysis
}

\author{
Irene Herruzo' ${ }^{1}$, Rafael Herruzo ${ }^{2 *}$, Maria Jose Vizcaino ${ }^{2}$ \\ ${ }^{1}$ Universidad Francisco de Vitoria, Madrid, Spain \\ ${ }^{2}$ Departamento de Medicina Preventiva y Salud Publica y Microbiologia, Universidad Automa de Madrid, \\ Madrid, Spain \\ Email: irene.herruzo@gmail.com, ${ }^{*}$ rafael.herruzo@uam.es, maria.vizcaino@uam.es
}

Received 22 April 2015; accepted 14 June 2015; published 19 June 2015

Copyright (C) 2015 by authors and Scientific Research Publishing Inc.

This work is licensed under the Creative Commons Attribution International License (CC BY).

http://creativecommons.org/licenses/by/4.0/

(c) $\underset{\mathrm{EY}}{\mathrm{i}}$ Open Access

\begin{abstract}
Objective: To determine whether there was any association between resistance to antibiotics and decreased susceptibility to antiseptics and disinfectants and their importance in clinical practice. Methods: We studied a large number of microorganisms isolated from ICU patients (high percentage of cases of antibiotic resistance). The antibiogram (Kirby-Bauer) was determined and, in parallel, the bactericidal effect was assessed by two methods, according to the product used: 1) Effect on rough material (endodontic files) in $10 \mathrm{~min}$, using five disinfectants; 2) Effect on a skin equivalent (sterile cotton cloth) in $\mathbf{3 0}$ sec, for two alcohol solutions. A predictive equation of the bactericidal effects versus microorganisms' antibiogram was obtained by multivariate methods. Results: Bactericidal efficacy was very similar for all the products with the exception of $1 \%$ povidone-iodine. Within each product there were no significant differences between the three groups of microorganisms: "Enterobacteria", "Non Fermentative Gram Negative Bacteria" and "cocci". Multivariate study only obtained one significant equation: $1 \%$ chlorhexidine resistance was directly correlated with aztreonam resistance $(O R=2.16)$, while resistance to imipenem and to phosphomycin acted as protection factors $(\mathrm{OR}<1)$. Conclusion: There is no necessary to change the indications for antiseptics or disinfectants in ICUs, except if aztreonam resistance is high. In which case is better to use greater concentration than $1 \%$ of Chlorhexidine.
\end{abstract}

\footnotetext{
${ }^{*}$ Corresponding author.
} 
Keywords

Predicted, Bactericidal-Effect, Disinfectants/Antiseptics, Antibiotic-Resistance

\section{Introduction}

The correlation between resistance to antibiotics and decreased susceptibility to disinfectants has been studied fairly extensively. For example, Barbee [1] established a correlation between resistance to gentamicin and a decreased susceptibility to propamidine, quaternary ammonium compounds, and ethidium bromide; Cookson [2] and Fayer [3] found decreased susceptibility to quaternary ammonium compounds in methicillin-resistant Staphylococcus aureus (MRSA) versus other variants of this microorganism susceptible to methicillin (MSSA). However, MRSA and MSSA were equally susceptible to phenols and chlorhexidine.

In an earlier study [4] we found that one of the disinfectants most used in high level disinfection, orthophthalaldehyde (OPA), when exposed to P. aeruginosa recently isolated from patients, produced a weaker bactericidal effect than on reference strains (ATCC). But when using different microorganisms, this correlation was already not in evidence [5].

The importance in clinical practice of the correlation between antibiotic resistance and decreased susceptibility to disinfectants and antiseptics is open to debate [6] [7]. Moreover, we need to bear in mind that MICs to disinfectants are calculated on $24 \mathrm{~h}$ of exposure (as with antibiograms), whereas in practice these products should act in just a few minutes [8].

It has been shown that it is possible for pathogenic agents to develop a greater tolerance to disinfectants to which they are exposed. However, this is of no great importance in clinical practice as these tolerance levels are low and disinfectants are used in high concentrations [6] [9] [10]-[12]. Looking at triclosan they discovered that at low concentrations there were indeed cases of resistance to this product, but this was of no consequence in normal practice as this compound was used at higher concentrations [13]-[15]. This is why Maillard [16] in 2007, believes that the lack of testing for bacterial resistance in clinical practice, and the inability to correlate the bacterial resistance found in in vitro experiments with real-life situations, stands in the way of forming any adequate assessment as to whether the bacterial resistance that is beginning to emerge in the healthcare environment should be (or not) a cause for real concern.

Other authors consider that the use of disinfectants and antibiotics can facilitate the development of resistance to antibiotics because they share with them certain mechanisms of action [6] [17]. But this does not explain why the use of antiseptics/disinfectants selects organisms that are naturally antibiotic-resistant or mutants that survive in nature [16] [18]-[20].

Apart from which, there are fundamental differences between the action mechanisms of antibiotics and those of disinfectants. Antibiotics are selectively toxic and generally they have a single point of action in bacteria, inhibiting a specific biosynthetic process. Disinfectants are not specific because they have a multiple toxicity effect or have various points of action within the cell [10] [12].

At all events there is a concern that extensive use of biocides could lead to a decrease in their efficacy by selecting resistant microorganisms, and it is therefore proposed in the future to monitor biocides so that, if strong resistance does occur, decisions can be taken immediately as to whether this substance is more of a risk than a benefit [21].

\section{Material and Methods}

Our aim was to determine whether there was any correlation between decreased bactericidal effect and antibiotic resistance using bivariate or multivariate methods, studying a large number of microorganisms recently isolated from ICU patients (with a greater frequency of antibiotic resistance, [22]). The main indication of antibiotics in ICUs was to treat nosocomial infections (confirmed or suspected), based on the antibiogram of isolated microorganisms from these patients.

The efficacy of antiseptics and disinfectants is measured with bactericidal effect in a given time. This was done by two different methods:

1) Determination of the bactericidal effect on a rough instrument model (endodontic files). 
The material used was the following.

- Disinfectants and antiseptics: 0.55\% ortho-phthalaldehyde (OPA) (Johnson \& Johnson Lab, New Brunswick, NJ, USA); 5\% benzalkonium chloride (Lonza Lab, Slough, UK), obtained by a 1:15 dilution of the product at $75 \%$ concentration; $1 \%$ povidone-iodine (Viatris Lab, San Fernando de Henares, Spain) obtained by a 1:10 dilution of the product at $10 \%$ concentration and $1 \%$ chlorhexidine (Lonza Lab, Slough, UK) obtained by a $1: 20$ dilution of the product at $20 \%$ concentration.

- 155 microorganisms recently isolated from ICU patients: S. aureus, E. faecalis, E. coli, Klebsiella, Enterobacter, Serratia, Proteus, Pseudomonas, Acinetobacter, and other Non Fermentative Gram Negative Bacteria.

- No. 25 endodontic files: These were of metal with a rough area of plastic therefore, difficult to disinfect.

- $0.25 \mathrm{~mm}$ diameter glass beads.

- Inhibitor of antiseptic action: Todd Hewitt broth (Difco, Detroit, MI, USA) + 6\% (v/v) of Tween 80, 0.5\% $(w / v)$ of sodium bisulfite $+0.5 \%(w / v)$ of sodium thiosulfate [4] [5] [23] [24].

- Blood agar plates.

Method [23] [24]:

The endodontic files (as a model of rough material to be disinfected), were contaminated with a microorganism suspension (48 h cultures that usually give counts of $10^{8} \mathrm{CFU} / \mathrm{ml}$ ) by immersion for $15 \mathrm{~min}$, after which they were left to dry for 15 min on a sterile surface (Petri dish not containing any culture medium and sterile, set at an incline of $30^{\circ}$ ). The file was then submerged in a tube with $7 \mathrm{~cm}$ of disinfectant for 10 min while stirring, after which time the file was transferred (aseptically) to a tube with $7 \mathrm{ml}$ of inhibitor and $0.5 \mathrm{~g}$ of $1 \mathrm{~mm}$ diameter glass beads. It was vortexed for $1 \mathrm{~min}$ at $1000 \mathrm{rpm}$, and, from it, aliquots (at least 2) of $0.1 \mathrm{ml}$ were obtained, which were used to seed culture plates (blood or Saboureaud agar for fungi). They were incubated at $37^{\circ} \mathrm{C}$ for 48 $\mathrm{h}$, after which the number of CFUs surviving exposure to the antimicrobial agent was counted. This number was compared with that found on the control dishes prepared using the same method as detailed above, but this time placing the germ-carrier into sterile distilled water instead of disinfectant; and in order to facilitate the microbial count the seeding was not done directly from the inhibitory broth, but instead by preparing 1:100 and 1:1000 serial dilutions.

The method used gave results that were in agreement with the European germ-carrier, which is of smooth glass (prEN 14561), but adjusting the cut-off point from $5 \log _{10}$ reduced to 3.5 for bacteria and fungi [4], as it involved passing a more difficult functional test, given that the germ-carrier had a rough surface.

2) Bactericidal effect on skin or equivalent [23] [24]

- Two alcohol-based antiseptics were used, chosen for their efficacy from among 8 products with different compositions:

*SAM (Solución Antiséptica de Manos: antiseptic hand scrub) alcohol + 0.4\% chlorhexidine + benzalkonium chloride (Inibsa SA Lab, Lliça de Vall, Spain)

*Sterillium ${ }^{\circledR}$ : alcohol + 0.2\% mecetronium (Bode Chemie Lab, Hamburg, Germany).

- 109 microorganisms recently isolated from ICU patients: S. aureus, E. faecalis, E. coli, Klebsiella, Enterobacter, Serratia, Proteus, Pseudomonas, Acinetobacter, and other Non Fermentative Gram Negative Bacteria.

- Germ carriers: skin or fabric (surgical cotton cloth) $0.5 \mathrm{~cm}$ in diameter, which gives similar results to skin.

- Inhibitor of antiseptic action: Todd-Hewitt broth (Difco, Detroit, MI, USA) + 6\% (v/v) of Tween 80, 0.5\% $(w / v)$ of sodium bisulfite $+0.5 \%(w / v)$ sodium thiosulfate. Blood agar dishes [4] [5] [23] [24].

Method:

The germ samples used were isolated from various patients in the ICU at La Paz Hospital.

The germ carrier of skin or rough fabric (as a model of human skin) $0.5 \mathrm{~cm}$ in diameter was contaminated with $10 \mu \mathrm{l}$ of microorganism suspension $\left(10^{9} \mathrm{CFU} / \mathrm{ml}\right)$ and left to dry for $15 \mathrm{~min}$ on a plate inclined at $30^{\circ}$. Next, this piece of fabric was placed in the antiseptic for $30 \mathrm{sec}$, withdrawn from the germicide with sterile tweezers, and submerged in a tube containing $2.5 \mathrm{ml}$ of inhibitor for $1 \mathrm{~min}$. After that it was vortexed at $1000 \mathrm{rpm}$ for 1 min. Next, 2 samples of $0.1 \mathrm{ml}$ of this suspension were seeded on plates of blood agar. The control samples followed the same processes as described above, except that instead of being passed through disinfectant they were passed through distilled water; finally, 2 dilutions were performed: one of 1:100 and the other of 1:1000.

Statistical analysis:

The results of the bactericidal effects obtained with both methods were expressed as a $\log _{10}$ reduction, ob- 
tained from the difference between the $\log _{10}$ of the control microorganisms and the $\log _{10}$ of the findings following the action of the disinfectant. When no surviving microorganism were obtained following the action of a disinfectant (which would be a $\log _{10}=-\infty$ ) a standardization was performed putting $5.5 \log _{10}$ as the reduction factor obtained after disinfection.

- Bivariate analysis: Student's t-test, ANOVA for the quantitative variables and $\chi^{2}$ for the qualitative variables with respect to the bactericidal effect and antibiotic resistance.

- Multivariate analysis: Logistic regression, using the resistance to different antibiotics as dependent variables and the bactericidal effect, the product, and the microorganism as independent variables.

The statistical significance assessment was performed by calculating the $-2 * \log$-likelihood. By default, 0.05 was used as the point of entry of one variable in the model, and 0.10 for its exit. The results were expressed in tables showing the variables finally included, together with their coefficient $b$, their associated standard error, the statistical significance, and lastly the term $e^{\beta}$, which represents the magnitude of their effect adjusted for the remaining variables, expressed as an odd ratio (OR) and their 95\% confidence interval. In addition, the overall goodness of fit of the models was assessed by graphic representation of the values for Susceptibility and 1-Specificity in ROC (Receiver Operating Characteristics) curves.

\section{Results}

In assessing the bactericidal effect, a different overall efficacy is found according to the product used (Table 1). Bactericidal efficacy was very similar for all the products with the exception of $1 \%$ povidone-iodine. Within each product there were no significant differences between the three groups of microorganisms: "Enterobacteria", "Non fermentative Gram negative bacteria (NFGNB)" and "cocci”

Comparing the product and the antibiogram with the bactericidal effect, we find the results shown in Table 2, the following of which are of special interest:

The bactericidal effect of OPA is similar in the presence of strains susceptible or resistant to every one of the tested antibiotics.

The bactericidal effect of chlorhexidine showed a significant $(p<0.05)$ correlation with resistance to levofloxacin and a nearly-significant ( $p$ between 0.05 and 0.1 ) correlation with resistance to sulfamethoxazole trimethoprim and phosphomycin, but in all these cases the antibiotic-resistant strains were more susceptible (had a stronger bactericidal effect) to chlorhexidine.

Table 1. Bactericidal effects of antiseptics and disinfectants, according to the various microorganisms.

\begin{tabular}{|c|c|c|c|c|}
\hline \multirow{2}{*}{ Disinfectant or antiseptic } & \multicolumn{4}{|c|}{ Type of microorganism } \\
\hline & Gram + & Enterobact & NFGNB & Overall \\
\hline 0,55\% Orto-phthalaldehyde & $\begin{array}{c}4.36 \pm 0.82 \\
(n=16)\end{array}$ & $\begin{array}{c}4.94 \pm 0.51 \\
(\mathrm{n}=72)\end{array}$ & $\begin{array}{c}5.03 \pm 0.64 \\
(n=67)\end{array}$ & $\begin{array}{r}4.93 \pm 0.64 \\
(n=155)\end{array}$ \\
\hline 1\% Chlorhexidine & $\begin{array}{c}3.94 \pm 1.09 \\
(\mathrm{n}=16)\end{array}$ & $\begin{array}{c}4.44 \pm 0.82 \\
(\mathrm{n}=72)\end{array}$ & $\begin{array}{c}4.11 \pm 0.71 \\
(\mathrm{n}=67)\end{array}$ & $\begin{array}{c}4.25 \pm 0.83 \\
(n=155)\end{array}$ \\
\hline 1\% Povidone-iodine & $\begin{array}{c}3.47 \pm 1.45 \\
(\mathrm{n}=16)\end{array}$ & $\begin{array}{c}2.98 \pm 0.78 \\
(\mathrm{n}=72)\end{array}$ & $\begin{array}{c}2.63 \pm 0.65 \\
(\mathrm{n}=67)\end{array}$ & $\begin{array}{r}2.88 \pm 0.86 \\
(\mathrm{n}=155)\end{array}$ \\
\hline 5\% Benzalkonium chloride & $\begin{array}{c}4.47 \pm 0.75 \\
(\mathrm{n}=16)\end{array}$ & $\begin{array}{c}4.51 \pm 0.69 \\
(\mathrm{n}=72)\end{array}$ & $\begin{array}{c}4.84 \pm 0.59 \\
(n=67)\end{array}$ & $\begin{array}{r}4.65 \pm 0.67 \\
(n=155)\end{array}$ \\
\hline $0.2 \%$ Mecetronium + alcohol & $\begin{array}{c}4.36 \pm 0.82 \\
(n=27)\end{array}$ & $\begin{array}{c}4.94 \pm 0.51 \\
(n=42)\end{array}$ & $\begin{array}{c}5.03 \pm 0.64 \\
(\mathrm{n}=40)\end{array}$ & $\begin{array}{r}4.83 \pm 1.24 \\
(\mathrm{n}=109)\end{array}$ \\
\hline 0.4\% Chlorhex $+0.1 \%$ Benz. Chlor + alcohol & $\begin{array}{c}4.36 \pm 0.82 \\
(n=27)\end{array}$ & $\begin{array}{c}4.94 \pm 0.51 \\
(n=42)\end{array}$ & $\begin{array}{c}5.03 \pm 0.64 \\
(\mathrm{n}=40)\end{array}$ & $\begin{array}{l}4.7 \pm 1.31 \\
(\mathrm{n}=109)\end{array}$ \\
\hline
\end{tabular}


Table 2. Bactericidal effects of antiseptics and disinfectants, according to their resistance to various antibiotics.

\begin{tabular}{|c|c|c|c|c|c|c|c|c|}
\hline \multirow{3}{*}{ Antibiotic } & \multicolumn{8}{|c|}{ Disinfectant or antiseptic } \\
\hline & \multicolumn{2}{|r|}{$\begin{array}{c}0,55 \% \\
\text { Ortho-phthalaldehyde }\end{array}$} & \multirow{2}{*}{$\begin{array}{c}\begin{array}{c}1 \% \\
\text { Chlorhex }\end{array} \\
\mathrm{M} \pm \mathrm{SD}\end{array}$} & \multirow{2}{*}{\begin{tabular}{c|c}
$\%$ \\
Pov-I \\
$\mathrm{M} \pm \mathrm{SD}$ \\
\end{tabular}} & \multirow{2}{*}{$\begin{array}{c}\begin{array}{c}5 \% \\
\text { C. benz }\end{array} \\
\text { M } \pm \text { SD } \\
\end{array}$} & \multirow[b]{2}{*}{$\%$ S or R } & \multirow{2}{*}{$\begin{array}{c}0.2 \% \text { Mecetronium } \\
+ \text { alcohol }\end{array}$} & \multirow{2}{*}{$\begin{array}{c}\text { 0.4\% Chlorhexidine + } \\
0.1 \% \text { Benz chlor + alcoho } \\
\mathrm{M} \pm \mathrm{SD}\end{array}$} \\
\hline & $\% \mathrm{~S}$ or $\mathrm{R}$ & $\mathbf{M} \pm \mathbf{S D}$ & & & & & & \\
\hline \multirow{2}{*}{$\begin{array}{l}\text { Sulfam- } \\
\text { trimethoprim }\end{array}$} & $\mathrm{S}=69 \%$ & $4.9 \pm 0.7$ & $4.1 \pm 0.8$ & $2.9 \pm 0.9$ & $4.8 \pm 0.6$ & $\mathrm{~S}=48 \%$ & $4.5 \pm 1.2$ & $4.7 \pm 1.3$ \\
\hline & $\mathrm{R}=31 \%$ & $4.9 \pm 0.7$ & $4.5 \pm 0.7 \&$ & $3.1 \pm 0.8$ & $4.9 \pm 0.7 \&$ & $\mathrm{R}=52 \%$ & $5.3 \pm 1.1$ & $4.9 \pm 1.3$ \\
\hline \multirow{2}{*}{ Cephalothin } & $\mathrm{S}=92 \%$ & $5 \pm 0.6$ & $4.3 \pm 0.7$ & $3 \pm 0.9$ & $4.7 \pm 0.7$ & $\mathrm{~S}=28 \%$ & $4.1 \pm 1.4$ & $4.3 \pm 1.5$ \\
\hline & $\mathrm{R}=8 \%$ & $5 \pm 0.6$ & $4.8 \pm 0.6$ & $3 \pm 0.6$ & $4.8 \pm 0.5$ & $\mathrm{R}=72 \%$ & $5.1 \pm 1$ & $4.9 \pm 1.2$ \\
\hline \multirow{2}{*}{ Levofloxacin } & $\mathrm{S}=35 \%$ & $4.9 \pm 0.7$ & $4 \pm 0.9$ & $2.7 \pm 0.8$ & $4.8 \pm 0.6$ & $\mathrm{~S}=77 \%$ & $5.2 \pm 0.9$ & $5 \pm 1$ \\
\hline & $\mathrm{R}=65 \%$ & $4.9 \pm 0.6$ & $4.3 \pm 0.7^{*}$ & $3 \pm 1$ & $4.7 \pm 0.7$ & $\mathrm{R}=23 \%$ & $5 \pm 1.2$ & $4.7 \pm 1.4$ \\
\hline \multirow{2}{*}{ Imipenem } & $\mathrm{S}=36 \%$ & $4.9 \pm 0.6$ & $4.1 \pm 0.8$ & $2.7 \pm 0.7$ & $4.8 \pm 0.6$ & $\mathrm{~S}=77 \%$ & $5.3 \pm 0.9$ & $5.1 \pm 1.1$ \\
\hline & $\mathrm{R}=64 \%$ & $4.9 \pm 0.6$ & $4.4 \pm 0.8$ & $3.1 \pm 1$ & $4.7 \pm 0.7$ & $\mathrm{R}=23 \%$ & $5.1 \pm 1$ & $5 \pm 1.2$ \\
\hline \multirow{2}{*}{ Tobramycin } & $\mathrm{S}=37 \%$ & $4.8 \pm 0.7$ & $4.3 \pm 0.8$ & $3 \pm 0.9$ & $4.7 \pm 0.7$ & $S=57 \%$ & $5.2 \pm 1$ & $5 \pm 1.2$ \\
\hline & $\mathrm{R}=63 \%$ & $5 \pm 0.6$ & $4.3 \pm 0.7$ & $3 \pm 0.9$ & $4.7 \pm 0.6$ & $\mathrm{R}=43 \%$ & $5.2 \pm 0.9$ & $4.9 \pm 1.1$ \\
\hline \multirow{2}{*}{ Ceftazidime } & $\mathrm{S}=54 \%$ & $4.9 \pm 0.6$ & $4.2 \pm 0.6$ & $3.1 \pm 0.9 \&$ & $4.6 \pm 0.6$ & $\mathrm{~S}=77 \%$ & $5.2 \pm 0.9$ & $5 \pm 1.1$ \\
\hline & $\mathrm{R}=46 \%$ & $5 \pm 0.7$ & $4.4 \pm 0.8$ & $2.8 \pm 0.9$ & $4.8 \pm 0.7^{*}$ & $\mathrm{R}=23 \%$ & $5.2 \pm 1.1$ & $4.9 \pm 1.3$ \\
\hline \multirow{2}{*}{ Gentamicin } & $\mathrm{S}=37 \%$ & $4.9 \pm 0.7$ & $4.2 \pm 0.9$ & $3.2 \pm 1$ & $4.8 \pm 0.6$ & $\mathrm{~S}=62 \%$ & $5.3 \pm 0.9$ & $5 \pm 1.1$ \\
\hline & $\mathrm{R}=63 \%$ & $4.9 \pm 0.6$ & $4.3 \pm 0.7$ & $2.9 \pm 0.8$ & $4.6 \pm 0.7$ & $\mathrm{R}=38 \%$ & $5.2 \pm 0.9$ & $5 \pm 1.1$ \\
\hline \multirow{2}{*}{ Amikacin } & $\mathrm{S}=85 \%$ & $4.8 \pm 0.7$ & $4.1 \pm 0.7$ & $3.1 \pm 1$ & $4.7 \pm 0.5$ & $\mathrm{~S}=76 \%$ & $5.3 \pm 1$ & $5.1 \pm 1.1$ \\
\hline & $\mathrm{R}=15 \%$ & $4.9 \pm 0.6$ & $4.3 \pm 0.8$ & $3 \pm 0.9$ & $4.7 \pm 0.7$ & $\mathrm{R}=24 \%$ & $5.2 \pm 1$ & $4.8 \pm 1.2$ \\
\hline \multirow{2}{*}{ Phosphomycin } & $S=72 \%$ & $5 \pm 0.7$ & $4 \pm 0.7$ & $3 \pm 1$ & $4.6 \pm 0.7$ & $\mathrm{~S}=86 \%$ & $5.2 \pm 1$ & $4.9 \pm 1.2$ \\
\hline & $\mathrm{R}=28 \%$ & $4.9 \pm 0.7$ & $4.4 \pm 0.7 \&$ & $3 \pm 0.9$ & $4.7 \pm 0.6$ & $\mathrm{R}=14 \%$ & $5.1 \pm 0.7$ & $5.1 \pm 0.5$ \\
\hline \multirow{2}{*}{ Tazobactam } & $\mathrm{S}=52 \%$ & $4.9 \pm 0.7$ & $4.2 \pm 0.7$ & $3.1 \pm 1$ & $4.7 \pm 0.6$ & $\mathrm{~S}=70 \%$ & $5.2 \pm 1$ & $5 \pm 1.1$ \\
\hline & $\mathrm{R}=48 \%$ & $5 \pm 0.6$ & $4.4 \pm 0.8$ & $2.8 \pm 0.8 \&$ & $4.7 \pm 0.6$ & $\mathrm{R}=30 \%$ & $5.2 \pm 0.9$ & $5.2 \pm 0.9$ \\
\hline \multirow{2}{*}{ Aztreonam } & $S=53 \%$ & $4.9 \pm 0.6$ & $4.2 \pm 0.7$ & $3.1 \pm 1$ & $4.7 \pm 0.6$ & $\mathrm{~S}=59 \%$ & $5.1 \pm 1$ & $4.8 \pm 1.2$ \\
\hline & $\mathrm{R}=47 \%$ & $4.9 \pm 0.6$ & $4.3 \pm 0.8$ & $2.8 \pm 0.8^{*}$ & $4.7 \pm 0.7$ & $\mathrm{R}=41 \%$ & $5.2 \pm 0.9$ & $5.2 \pm 1^{*}$ \\
\hline
\end{tabular}

$*=p<0.05$ between the bactericidal effect of the $\mathrm{S}$ or R microorganisms in an antibiotic and the specific disinfectant or antiseptic. \& $=p>0.05$, but $<0.1$.

With povidone-iodine we found that the resistance to three antibiotics-aztreonam, ceftazidime, and tazobactam-were correlated with a weaker bactericidal effect for the antiseptic, but of these, only aztreonam reached a level of statistical significance $(p<0.05)$.

Benzalkonium chloride showed two types of correlation: the greatest susceptibility to the disinfectant was correlated with microorganisms most sensitive to aztreonam $(p<0.05)$, while the strains resistant to sulfamethoxazole trimethoprim exhibited a weaker bactericidal effect, although with these their $p$ was between 0.05 and 0.1 .

Of the two alcohol solutions, only alcohol + chlorhexidine + benzalkonium chloride showed a significant result, a stronger bactericidal effect being correlated with resistance to aztreonam.

With the data from the previous tables we could be sure that the resistance to the various antibiotics was of little relevance when looking for variations in the sensitivity to disinfectants, as this did not vary because the microorganisms were antibiotic-resistant, and in the few significant cases antibiotic-resistance showed a significant correlation with greater susceptibility to antiseptics and disinfectants (3 cases) than vice-versa (1 case). 
Multivariate analysis:

We carried out a multivariate study of the bactericidal effects of disinfectants and antiseptics as against their antibiotic resistance, according to the type of microorganism; this gave us different results depending on the bactericidal effect cut-off point.

We defined antiseptic or disinfectant resistance as having a bactericidal effect on rough-germ-carrier of less than $3.5 \log _{10}$ which was defined as a "disinfection failure" in a previous work [4]. The microorganisms and S or $\mathrm{R}$ to antibiotics were included as predictive variables.

Only one logistic regression equation with a good fit was obtained:

Resistance vs. Susceptibility to $1 \%$ chlorhexidine: $\mathrm{P} / 1-\mathrm{P}=0.28-0.97$ (imipenem) +0.77 (aztreonam) -0.99 (phosphomycin)

In other words, $1 \%$ chlorhexidine resistance was directly correlated with aztreonam resistance $(\mathrm{OR}=2.16)$, while resistance to imipenem and to phosphomycin acted as protection factors $(\mathrm{OR}<1)$. In this case the microorganism did not influence the fit of the equation, which was why it was not included as a predictive variable.

\section{Discussion}

The bactericidal method allowed a true assessment of the antimicrobial efficacy of antiseptics and disinfectants, so that while it was possible to establish a correlation between antibiotic resistance and decreased efficacy of those biocides in the time indicated for them, it would be necessary to adjust the standards of asepsis and disinfection according to the antibiotic-resistant microorganisms actually obtained or that could be expected (based on previous treatments, etc.) in a patient, mainly if they are in ICUs [22].

Overall, however, and after investigating a large number of microorganisms, this correlation was not a factor, and even in those few cases in which it was of significance, the tendency was in the opposite direction, i.e. antibiotic resistance correlated with greater susceptibility to antiseptics and disinfectants. This means that antibiotic resistance modified chemical structures or reactions that had nothing to do with those responsible for decreased biocide susceptibility; one could even say that these modifications meant a selective disadvantage not only as regards proliferation of microorganisms in their natural reservoirs, but also in the presence of antiseptics and disinfectants.

Another aspect to consider is the bactericidal effect cut-off point. The reduction of $3.5 \log _{10}$ was the best, given the type of germ-carrier used, as it equated to what in clinical practice would be regarded as a failure of disinfection or antisepsis, but with this cut-off point resistance to any antibiotic, after checking the effect of other variables in multivariate methods, was scarcely apparent (except in the case of chlorhexidine, a product that acts on the cytoplasmic wall and proteins, and resistance to aztreonam, an antibiotic that acts on the wall, with an OR of 2.1; imipenem and phosphomycin also entered the equation, but as protection factors, despite the fact that they too act on the bacterial wall). This disinfection failure, can be interesting due to a great use of chlorhexidine in modern hospital mainly in ICU and the great percentage of resistance to aztreonam in Enterobater or Serratia (>60\% according ENVIN-HELIC multicenter study, 2013, [25]). In these cases, greater concentration of $1 \%$ chlorhexidine, sould be used, e.g. $2 \%$, as it is included in some Guides [26]-[28].

No significant disinfection or antisepsis failure was found in the remaining products, associated to antibiotic-resistance.

If we extend the cut-off point to $5 \log _{10}$ reduced, the bacteria are classed as "sensitive" or "extremely sensitive" to biocides and make it possible to find better fits in the multivariate equations, like resistance to aminoglycosides and beta-lactams, but acting as protection factors (whilst more resistant to these antibiotics, they are more susceptible to OPA and benzalkonium chloride). Much the same happens with the resistance to quinolones, phosphomycin and tazobactam in relation to the susceptibility to chlorhexidine or OPA. Lastly, normal susceptibility to these two disinfectants correlated only with resistance to sulfamethoxazole trimethoprim.

\section{Conclusions}

- On the whole, there was no correlation between antibiotic resistance and decreased susceptibility to antiseptics or disinfectants, but if the number of included microorganisms is high, it is possible to predict susceptibility or some resistance to divers antiseptic or disinfectants, according to antibiotic resistance of bacteria.

- There is no necessity to change the indications for these products in ICUs and other departments in which a higher proportion of antibiotic-resistant microorganisms are isolated, except for $1 \%$ chlorhexidine, due to 
aztreonam-resistance is a risk factor to failure. If aztreonam resistance is high in an ICU (e.g. in Enterobacter or Serratia), to use a chlorhexidine concentration greater of $1 \%$ (e.g., $2 \%$ ).

- In the contrary sense, resistance to other antibiotics (except sulfamethoxazole trimethoprim) acts as protection factors of decreased susceptibility of antiseptics or disinfectants.

\section{Acknowledgements}

Acknowledgements to Mayca Uriarte Fernandez.

\section{Conflict of Interest}

None.

\section{References}

[1] Barbee, S.L., Weber, D.J., Sobsey, M.D. and Rutala, W.A. (1999) Inactivation of Cryptosporidium parvum Oocyst Infectivity by Disinfection and Sterilization Processes. Gastrointestinal Endoscopy, 49, 605-611. http://dx.doi.org/10.1016/S0016-5107(99)70389-5

[2] Cookson, B.D., Bolton, M.C. and Platt, J.H. (1991) Chlorhexidine Resistance in Methicillin-Resistant Sthaphylococcus aureus or Just an Elevated MIC? An in Vitro and in Vivo Assessment. Antimicrobial Agents and Chemotherapy, 35, 1997-2002.http://dx.doi.org/10.1128/AAC.35.10.1997

[3] Fayer, R., Graczyk, T.K., Cranfield, M.R. and Trout, J.M. (1996) Gaseous Disinfection of Cryptosporidium parvum Oocysts. Applied and Environmental Microbiology, 62, 3908-3909.

[4] Herruzo-Cabrera, R., Vizcaíno-Alcaide, M.J. and Fernández-Aceñero, M.J. (2004) The Influence of Laboratory Adaptation on Test Strains, Such as Pseudomonas aeruginosa, in the Evaluation of the Antimicrobial Efficacy of Ortho-Phthalaldehyde. The Journal of Hospital Infection, 57, 217-222. http://dx.doi.org/10.1016/j.jhin.2004.01.031

[5] Herruzo, R., Vizcaino, M.J., Herruzo, I. and de la Cruz, J.J. (2009) Can the Antibiotic Resistance of a Microorganism Predict Decreased Bactericidal Efficacy of Disinfectants? Application to OPA and Other Products. European Journal of Clinical Microbiology \& Infectious Diseases, 28, 539-541. http://dx.doi.org/10.1007/s10096-008-0648-6

[6] Moken, M.C., McMurry, L.M. and Levy, S.B. (1997) Selection of Multiple-Antibiotic-Resistant (mar) Mutants of Escherichia coli by Using the Disinfectant Pine Oil: Roles of the Mar and acrAB loci. Antimicrobial Agents and Chemotherapy, 41, 2770-2772.

[7] Rutala, W.A. and Weber, D.J. (2001) Surface Disinfection: Should We Do It? The Journal of Hospital Infection, 48, S64-S68. http://dx.doi.org/10.1016/S0195-6701(01)90017-9

[8] Stickler, D.J. (2002) Susceptibility of Antibiotic-Resistant Gram-Negative Bacteria to Biocides: A Perspective from the Study of Catheter Biofilms. Journal of Applied Microbiology, 92, 163S-170S. http://dx.doi.org/10.1046/j.1365-2672.92.5s1.6.x

[9] Scott, E., Bloomfield, S.F. and Barlow, C.G. (1982) An Investigation of Microbial Contamination in the Home. Journal of Hygien, 89, 279-293. http://dx.doi.org/10.1017/S0022172400070819

[10] Rutala, W.A. (1993) Sporicidal Activity of Chemical Sterilants Used in Hospitals. Infection Control and Hospital Epidemiology, 14, 713-718. http://dx.doi.org/10.2307/30148350

[11] McMurry, L.M., Oethinger, M. and Levy, S.B. (1988) Triclosan Targets Lipid Synthesis. Nature, 394, 531-532. http://dx.doi.org/10.1038/28970

[12] Rusin, P., Orosz-Coughlin, P. and Gerba, C. (1998) Reduction of Faecal Coliform, Coliform and Heterotrophic Plate Count Bacteria in the Household Kitchen and Bathroom by Disinfection with Hypochlorite Cleaners. Journal of Applied Microbiology, 85, 819-828. http://dx.doi.org/10.1046/j.1365-2672.1998.00598.x

[13] Bueumer, R., Bloomfield, S.F., Exner, M., Fara, G. and Scott, E.A. (1999) The Need for a Home Hygiene Policy and Guidelines on Home Hygiene. Annali di Igiene, 11, 11-26.

[14] Gilbert, P. and McBain, A.J. (2003) Potential Impact of Increased Use of Biocides in Consumer Products on Prevalence of Antibiotic Resistance. Clinical Microbiology Reviews, 16, 189-208. http://dx.doi.org/10.1128/CMR.16.2.189-208.2003

[15] Sheldon Jr., A.T. (2005) Antiseptic "Resistance”: Real or Perceived Threat? Clinical Infectious Diseases, 40, 16501656. http://dx.doi.org/10.1086/430063

[16] Maillard, J.Y. (2007) Bacterial Resistance to Biocides in the Healthcare Environment: Should It Be of Genuine Concern? Journal of Hospital Infection, 65, 60-72. http://dx.doi.org/10.1016/S0195-6701(07)60018-8 
[17] Levy, S.B. (2000) Antibiotic and Antiseptic Resistance: Impact on Public Health. The Pediatric Infectious Disease Journal, 19, S120-S122. http://dx.doi.org/10.1097/00006454-200010001-00008

[18] McDonnell, G. and Russell, A.D. (1999) Antiseptics and Disinfectants: Activity, Action, and Resistance. Clinical Microbiology Reviews, 12, 147-179.

[19] Gerba, C.P. and Rusin, P. (2001) Relationship between the Use of Antiseptics/Disinfectants and the Development of Antimicrobial Resistance. In: Rutala, W.A., Ed., Disinfection, Sterilization and Antisepsis: Principles and Practices in Healthcare Facilities, Association for Professional in Infection Control and Epidemiology, Washington DC, 187-194.

[20] Russell, A.D. (2001) Principles of Antimicrobial Activity and Resistance. In: Block, S.S., Ed., Disinfection, Sterilization, and Preservation, Lippincott Williams \& Wilkins, Philadelphia, 31-55.

[21] Syverson, E.A. (2006) Reduction of Hand Bacteria: A Comparative Study among Common Antiseptics. Saint Martin's University Biology Journal, 1, 75-84.

[22] Oteo, J., Hernandez, J.M., Espasa, M., Fleites, A., Saez, D., Bautista, V., et al. (2013) Emergence of OXA-48-Producing Klebsiella pneumoniae and the Novel Carbapenemases OXA-244 and OXA-245 in Spain. Journal of Antimicrobial Chemotherapy, 68, 317-321. http://dx.doi.org/10.1093/jac/dks383

[23] Herruzo-Cabrera, R., Vizcaino-Alcaide, M.J., Mayer, F. and Rey-Calero, J. (1992) A New in Vitro Model to Test the Effectiveness of Topical Antimicrobial Agents. Use of an Artificial Eschar. Burns, 18, 35-38. http://dx.doi.org/10.1016/0305-4179(92)90117-D

[24] Herruzo, R., Vizcaino, M.J. and Herruzo, I. (2010) In Vitro-In Vivo Sequence Studies as a Method of Selecting the Most Efficacious Alcohol-Based Solution for Hygienic Hand Disinfection. Clinical Microbiology and Infection, 16, 518-523. http://dx.doi.org/10.1111/j.1469-0691.2009.02827.x

[25] Estudio Nacional de Vigilancia de la Infeccion Nosocomial en Servicios de Medicina Intensiva. ENVIN-HELICS, 2013.

[26] Moureau, N. (2009) Preventing Peripheral Intravenous Life Infections: Recommendations for Healthcare Facilities. Journal of the Association for Vascular Access, 14, 187-190. http://dx.doi.org/10.2309/java.14-4-3

[27] O’Grady, N.P., Alexander, M., Burns, L.A., Dellinger, E.P., Garland, J., Heard, S.O., et al. (2011) Guidelines for the Prevention of Intravascular Catheter-Related Infections. CDC.

[28] CDC (2014) Carbapenem-Resistant Enterobacteriaceae (CRE) Control and Prevention Toolkit.

\section{Abbreviations Used in This Paper}

ICU: intensive care unit;

OR: odds-ratio;

MRSA: methicillin-resistant Staphylococcus aureus;

MSSA: susceptible to methicillin;

OPA: ortho-phthalaldehyde;

ATCC: American Type Culture Collection;

MIC: Minimal Inhibitory Concentration;

CFU: colony forming unit; preen: pre-European Norm;

ANOVA: analysis of variance;

$\chi^{2}$ : chi-squared;

ROC: Receiver Operating Characteristics;

NFGNB: Non fermentative Gram negative bacteria;

ENVIN-HELIC: study of surveillance of ICU-nosocomial infections in Europe. 